\title{
Surface thermal perturbations of the recent past at low latitudes - inferences based on borehole temperature data from Eastern Brazil
}

\author{
V. M. Hamza ${ }^{1}$, A. S. B. Cavalcanti ${ }^{1,2}$, and L. C. C. Benyosef ${ }^{1}$ \\ ${ }^{1}$ Observatório Nacional - ON/MCT, Rua General José Cristino, 77, São Cristóvão, Rio de Janeiro, Brazil \\ ${ }^{2}$ Exploration and Production - SERV/US-SUB/GDS, PETROBRÁS S/A, Macaé, Rio de Janeiro
}

Received: 1 March 2007 - Published in Clim. Past Discuss.: 8 March 2007

Revised: 25 May 2007 - Accepted: 24 August 2007 - Published: 28 August 2007

\begin{abstract}
Borehole temperature data from the eastern parts of Brazil has been examined in an attempt to extract information on surface thermal perturbations of the recent past at low latitudes. Forward models were employed in the analysis of temperature logs from 17 localities and, in addition, Bayesian inverse modeling was carried out for data from 14 selected sites. The model results have allowed determination of the magnitude as well as the duration of ground surface temperature (GST) changes in three major geographic zones of Brazil. Prominent among such changes are the warming episodes that occurred over much of the subtropical highland regions in the southeastern parts of Brazil. The present magnitude of GST changes in this region are in the range of 2 to $3.5^{\circ} \mathrm{C}$ but have had their beginning during the early decades of the 20th century. Nearly similar trends are also seen in temperature-depth profiles of bore holes in the subtropical humid zones of the interior and coastal areas of southern Brazil. The data from semi arid zones of northeast Brazil also indicate occurrence of surface warming events but the magnitudes are in the range of 1.4 to $2.2^{\circ} \mathrm{C}$ while the duration of the warming event is larger, extending back into the last decades of the 19th century. There are indications that changes in both climate and vegetation cover contribute to variations in GST. Thus the magnitudes of GST variations are relatively large in localities which have undergone changes in vegetation cover. Also there are indications that GST changes are practically insignificant in areas of tropical rain forest. Another important result emerging from model studies is that the climate was relatively cooler during the 17 th and 18th centuries. The climate histories, deduced from geothermal data, are found to be consistent with results of available meteorological records in southern Brazil. Comparative studies also indicate that the magnitudes and duration of recent climate changes in southern and eastern Brazil are similar to those found in other continental areas such as North America, Asia and Europe.
\end{abstract}

Correspondence to: V. M. Hamza

(hamza@on.br)

\section{Introduction}

Geothermal methods have been employed during the last few decades for extracting information on climate changes of the recent past in several regions of the northern hemisphere (e.g. Cermak, 1971; Lachenbruch et al., 1982; Beltrami et al., 1992; Bodri and Cermak, 1995; Duchkov and Sokolova, 1998; Huang et al., 2000; Harris and Chapman, 2001; Majorowicz and Safanda, 2001; Golovanova et al., 2001; Beltrami and Burlon, 2004; Pollack and Smerdon, 2004). A review of many recent studies and the associated methods can be found in Pollack and Huang (2000). Nevertheless, very few attempts have been made in using geothermal data for examining climate variations in low latitudes of the southern hemisphere. Among the studies in this category are the works carried out in Australia (Cull, 1979, 1980; Torok and Nicholls, 1996; Taniguchi et al., 1999a, b; Appleyard, 2005; Pollack et al., 2006), Brazil (Hamza, 1991; Hamza, 1998; Hamza et al., 1991; Cavalcanti and Hamza, 2001; Cerrone and Hamza, 2003) and South Africa (Tyson et al., 1998; Jones et al., 1999). Much of the work carried out in Brazil remain as publications of limited access, such as internal reports (Hamza et al., 1978, 1987; Eston et al., 1982), academic theses (Vitorello, 1978; Araújo, 1978; Santos, 1986; Ribeiro, 1988; Del Rey, 1989; Cavalcanti, 2003) and meeting proceedings (Ribeiro, 1991; Souza et al., 1991; Cavalcanti and Hamza, 2001; Cerrone and Hamza, 2003; and Conceição and Hamza, 2006). In the present work we provide a synthesis of some of these recent works, with emphasis on the results discussed by Hamza and Cavalcanti (2001) and Cavalcanti (2003).

As prelude to the discussion of results presented in this work we provide first a brief description of the sources and characteristics of the geothermal data employed and the criteria used for data selection. Details of the methods used for extracting information on past climate are set out in the next section. The results obtained in model simulations of temperature-depth profiles are classified into groups, representative of the major geographic zones. Finally, the climate

Published by Copernicus Publications on behalf of the European Geosciences Union. 
history of Brazil deduced from geothermal data is compared with results of meteorological records of the last century and also with geothermal climate reconstructions from other continental areas.

\section{Characteristics of the data base}

According to the recent compilations carried out by the National Observatory (Observatório Nacional - ON/MCT) geothermal measurements have been carried out in 434 localities in Brazil (Hamza et al., 2005). Most of the earlier data were acquired as parts of basic research projects for heat flow determinations and also as parts of applied research projects for oil exploration and geothermal energy assessments. The focus of data acquisition in the earlier works has been on determining temperature gradients in the deeper parts of the boreholes.

The characteristics of these data sets are variable, depending on the methods used for primary data acquisition. Of these, only the ones acquired using the so-called conventional method (Hamza and Muñoz, 1996; Hamza et al., 2005) provide direct information on the vertical distribution of temperatures at shallow depths and hence are potentially suitable for climate related investigations. The conventional method has been employed for geothermal studies in 129 localities, which is slightly less than $30 \%$ of the overall data set. It includes mainly temperature logs in bore holes and wells and thermal property measurements on samples representative of local geologic formations. In some cases estimation of radiogenic heat production was also carried out. The details of the experimental techniques employed for temperature and thermal conductivity measurements have been discussed in several academic theses (e.g. Vitorello, 1978; Araújo, 1978; Del Rey, 1989) and in publications dealing with heat flow measurements (Hamza et al., 1987; Hamza and Muñoz, 1996; Gomes and Hamza, 2005). A direct evaluation of the quality of data acquired in the earlier works is a difficult task since the experimental techniques used for temperature and thermal conductivity measurements have undergone substantial changes over the last few decades.

The sources of conventional data sets employed in the present work may be considered as falling into three main groups:

1. That acquired during the decade of 1970 in the southern and eastern parts of Brazil. Most of this data has been published in the Brazilian Geothermal Data Collection - Volume 1 (Hamza et al., 1978). Some of these data were used in academic theses of the late 1970s (Vitorello, 1978 and Araújo, 1978) and related publications (Vitorello et al., 1978; Hamza, 1982);

2. That acquired during the decade of 1980, mainly in the state of São Paulo, as parts of hydrocarbon and geothermal energy exploration programs. Some of these data were reported as parts of academic theses of the 1980s (Santos, 1986; Ribeiro, 1988; Del Rey, 1989) and related publications (Santos et al., 1986; Del Rey and Hamza, 1989; Hamza et al., 1987);

3. Recent data acquired since the year 2000, mainly in the state of Rio de Janeiro and neighboring areas. Some of these have been employed in geothermal climate change studies of the state of Rio de Janeiro (Cerrone and Hamza, 2003; Hamza et al., 2003) and in mapping heat flow variations in the coastal area of southeast Brazil (Gomes, 2003; Gomes and Hamza, 2005).

\section{Selection criteria for climate studies}

The characteristics of the conventional (CVL) data set were examined carefully to screen out records with indications of possible perturbations arising from non-climatic effects. Also, it was necessary to eliminate those which do not provide fairly reliable determinations of both the steady and the transient components of the subsurface thermal field. In an attempt to guarantee the reliability of the data set the following quality assurance conditions were imposed:

1. The borehole is sufficiently deep that the lower section of the temperature-depth profile allows a reliable determination of the geothermal gradient, presumably free of the effects of recent climate changes. Order of magnitude calculations indicate that surface temperature changes of the last centuries would penetrate to depths of nearly $150 \mathrm{~m}$, in a medium with a thermal diffusivity of $10^{-6} \mathrm{~m}^{2} / \mathrm{s}$. Thus boreholes of at least $200 \mathrm{~m}$ deep are necessary for a reliable determination of the local geothermal gradient. The choice of this depth limit is rather arbitrary since the possibility that low amplitude climate signals of earlier periods are present at larger depths of up to several hundreds of meters cannot entirely be ruled out. However it is a reasonable compromise for examining subsurface thermal effects of ground surface temperature (GST) variations of the last few centuries;

2. The time elapsed between cessation of drilling and the temperature $\log$ is at least an order of magnitude large compared to the duration of drilling, minimizing thereby the influence of eventual thermal perturbations generated during the drilling activity;

3. The temperature-depth profile is free from the presence of any significant non-linear features in the bottom parts of the borehole, usually indicative of advection heat transfer by fluid movements, either in the surrounding formation or in the borehole itself;

4. The elevation changes at the site and in the vicinity of the borehole are relatively small so that the topographic 
perturbation of the subsurface temperature field at shallow depths is not significant; and

5. The lithologic sequences encountered in the borehole have relatively uniform thermal properties and are of sufficiently large thickness that the gradient changes related to variations in thermal properties does not lead to systematic errors in the procedure employed for extracting the climate related signal.

Out of a total of 129 conventional temperature logs only 17 were found to satisfy the above set of quality assurance conditions. The sites of these selected boreholes are distributed in the eastern parts of Brazil (in the states of Santa Catarina, Paraná, São Paulo, Minas Gerais, Rio de Janeiro and Bahia). The geographic distributions of the overall and selected data sets are illustrated in Fig. 1. Also outlined in this figure are the major climate zones of Brazil. The majority of the selected temperature logs are from boreholes with depths greater than $200 \mathrm{~m}$. Some log data for depths less than $200 \mathrm{~m}$ were also considered, as these are found to provide complementary information subsurface temperature fields at shallow depths which may be compared with those encountered in areas where deeper boreholes are situated. The updated version of the IHFC Geothermal Climate database provides more detailed information about the boreholes selected in the present work, including the temperature log data.

Most of the data sets acquired during the decades of 1970 and 1980 have temperature logs with measurements at depth intervals of ten to twenty meters. In more recent logs measurements have been made at intervals of two meters. Such detailed logs contain valuable information on recent climate changes and also provide more robust estimates of the background temperature gradients. Data from boreholes with depths shallower than 150 meters were not considered in the present work in view of the potential uncertainties in the determination of the local undisturbed gradient and consequent difficulties in extraction of the climate signal. On the other hand, information on climate changes of the recent past available in such logs may be used in obtaining qualitative assessment of GST changes. Also, data acquired at shallow depths of less than $20 \mathrm{~m}$ were excluded from analyses for climate changes, avoiding thereby eventual perturbing effects of diurnal and seasonal variations in the reconstruction of surface temperature history. Information on the locations of borehole sites, elevation, depth ranges of temperature measurements and period of data acquisition are summarized in the Table 1. In these tables the selected data sets are classified into groups following the three major geographic sectors, designated here as subtropical highlands, subtropical humid zones (of the interior and of the coastal areas) and semiarid zones. The area extents of these geographic sectors are in large part similar to the prevailing climate zones indicated in Fig. 1.

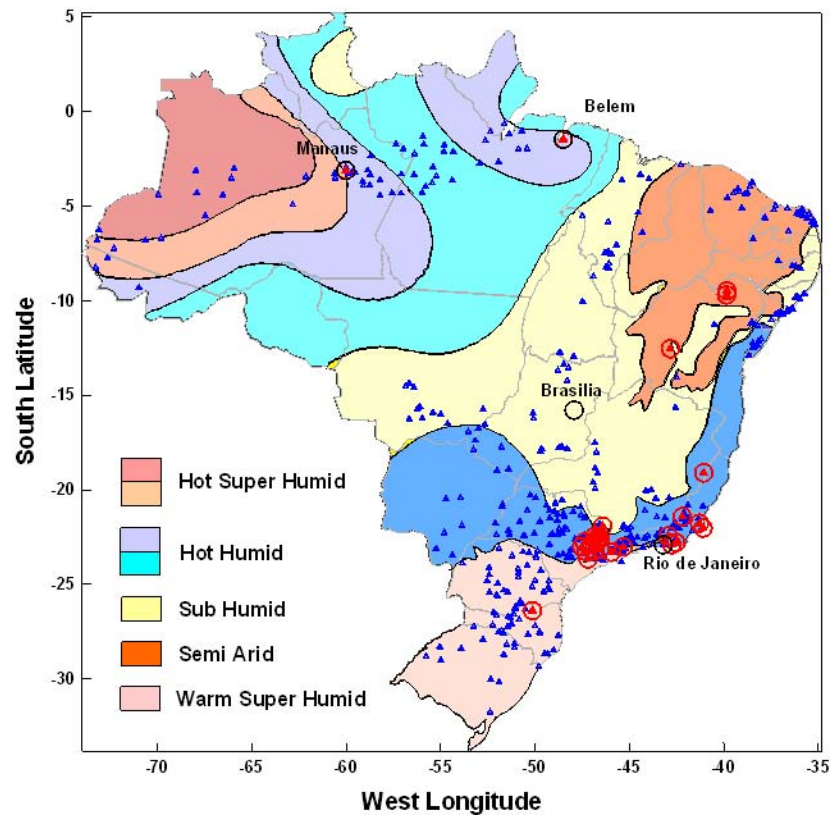

Fig. 1. Locations of geothermal measurements (solid triangles) and data sets selected for ground surface temperature variations (triangles enclosed by open circles) in the study area. Also shown in this figure are the major climate zones of Brazil.

\section{Methods employed in data analysis}

Both forward and inverse methods were employed in data analysis. The basic forward modeling approach has been discussed extensively in the literature (Birch, 1948; Cermak, 1971; Vasseur et al., 1983; Lachenbruch et al., 1986, 1988). For the case where surface temperature variation can be represented by a power law relation, analytic solutions are readily available. Thus, for a linear (or ramp type) change in surface temperature the relation between the amplitude of the climate signal $(\Delta \mathrm{T})$ and the time elapsed $(\mathrm{t})$ at any depth $(\mathrm{z})$ is given by the relation (Carslaw and Jaeger, 1959):

$\Delta T(z)=4 \Delta T i^{2} \operatorname{erfc}(z / \sqrt{4 \kappa t})$

where $\mathrm{i}^{2}$ erfc is the second integral of the complementary error function and $\kappa$ the thermal diffusivity of the medium. The best fitting ramp function is obtained by inverting the above relation using iterative procedures such as linearized Newton's method. The iterative procedure for this model, referred to as Ramp Inversion (Chisholm and Chapman, 1992; Golovanova et al., 2001; Roy et al., 2002), allows simultaneous determination of the magnitude of surface temperature change and the period of its occurrence. The main limitation of the forward model approach is that it resolves mainly the first-order features in the GST history. This is a consequence of the implicit assumption that the bottom parts of the log data, employed in determination of background temperature gradients, are free of transient perturbations. 
Table 1. Basic data on temperature-depth profiles selected for climate studies in eastern Brazil. The climate zones of the localities are indicated by asterisk marks (* - Subtropical high land; ** - Subtropical humid; *** - Semi-arid). The references are: 1- Del Rey (1986); 2Del Rey and Hamza (1989); 3- Araujo (1978); 4- Cerrone and Hamza (2003); 5- Gomes (2003); 6- Gomes and Hamza (2005); 7- Hamza et al. (1978); 8- Vitorello et al. (1978); 9- Hamza (1987).

\begin{tabular}{|c|c|c|c|c|c|}
\hline Borehole & Locality & $\begin{array}{l}\text { S. Latitude/ } \\
\text { W. Longitude }\end{array}$ & $\begin{array}{l}\text { Depth } \\
\text { (m) }\end{array}$ & Log Year & References \\
\hline AL-2 & A. Lindóia* & $\begin{array}{ll}22^{\circ} & 29^{\prime} \\
46^{\circ} & 38^{\prime}\end{array}$ & 200 & 1982 & 1,2 \\
\hline AM-1 & Amparo* & $\begin{array}{l}22^{\circ} 43^{\prime} \\
46^{\circ} 46^{\prime}\end{array}$ & 204 & 1982 & 1,2 \\
\hline $\mathrm{CO}-1$ & Cosmópolis* & $\begin{array}{l}23^{\circ} 43^{\prime} \\
47^{\circ} 12^{\prime}\end{array}$ & 210 & 1982 & 1,2 \\
\hline JAC15 & Jacareí* & $\begin{array}{l}23^{\circ} 17^{\prime} 44^{\prime \prime} \\
45^{\circ} 57^{\prime} 20^{\prime \prime}\end{array}$ & 268 & 1986 & 9 \\
\hline RF-1 & Rafard* & $\begin{array}{l}23^{\circ} 00^{\prime} \\
47^{\circ} 31^{\prime}\end{array}$ & 194 & 1982 & 1,2 \\
\hline IT-1 & $\mathrm{Itu}^{*}$ & $\begin{array}{ll}23^{\circ} & 15^{\prime} \\
47^{\circ} & 19^{\prime}\end{array}$ & 177 & 1982 & 1,2 \\
\hline JD-1 & Jundiaí* & $\begin{array}{l}23^{\circ} 10^{\prime} \\
46^{\circ} 52^{\prime}\end{array}$ & 172 & 1982 & 1,2 \\
\hline $\mathrm{SN}-1$ & Serra Negra* & $\begin{array}{l}22^{\circ} 36^{\prime} \\
46^{\circ} 32^{\prime}\end{array}$ & 184 & 1982 & 1,2 \\
\hline PC-1 & P. Caldas* & $\begin{array}{l}21^{\circ} 55^{\prime} \\
46^{\circ} 25^{\prime}\end{array}$ & 214 & 1976 & 3 \\
\hline PP-1 & Papanduva** & $\begin{array}{l}26^{\circ} 23^{\prime} \\
50^{\circ} 08^{\prime}\end{array}$ & 260 & 1976 & 7,8 \\
\hline LP-1 & Seropédica** & $\begin{array}{l}22^{\circ} 45^{\prime} 58^{\prime \prime} \\
43^{\circ} 39^{\prime} 15^{\prime \prime}\end{array}$ & 300 & 2001,2003 & 4,6 \\
\hline SR-9 & S. Sebastião** & $\begin{array}{l}23^{\circ} 48^{\prime} \\
45^{\circ} 25^{\prime}\end{array}$ & 188 & 1991 & 9 \\
\hline J-CLP7 & Jacobina $* * *$ & $\begin{array}{l}11^{\circ} 10^{\prime} 50^{\prime \prime} \\
40^{\circ} 31^{\prime} 06^{\prime \prime}\end{array}$ & 443 & 1976 & 7,8 \\
\hline AR-1 & Arraial $* * *$ & $\begin{array}{l}12^{\circ} 32^{\prime} \\
42^{\circ} 50^{\prime}\end{array}$ & 169 & 1976 & 7,8 \\
\hline CA-1019 & Caraiba-1*** & $\begin{array}{llll}09^{\circ} & 28^{\prime} & 12^{\prime \prime} \\
39^{\circ} & 50^{\prime} & 09^{\prime \prime}\end{array}$ & 511 & 1976 & 7,8 \\
\hline CA-F98 & Caraiba-2**** & $\begin{array}{ll}09^{\circ} 21^{\prime} 49^{\prime \prime} \\
39^{\circ} 05^{\prime} 03^{\prime \prime}\end{array}$ & 300 & 1976 & 7,8 \\
\hline PF-1 & Poço Fora ${ }^{* * *}$ & 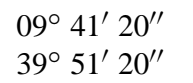 & 230 & 1976 & 7,8 \\
\hline
\end{tabular}

The basic steps in forward model approach include identification and separation of the steady and transient components present in temperature profiles at shallow depths. The steady state component is determined by the flow of heat from the interior of the Earth while the transient component is induced by downward propagation of a climate related thermal signal induced at the surface. Usually a linear fit to the deeper portion of the log data, where the climate perturbation is practically absent, allows determination of the local temperature gradient. However some care is necessary in selecting the depth interval for determination of the gradient. If the temperature gradient is calculated using a small subset of data from the lowermost part of the borehole its standard deviation $\left(\sigma_{G}\right)$ is likely to be relatively large, a consequence of the large root mean square (rms) deviation associated with the small number of data points. Progressive inclusion of data from the overlying parts in least square analysis leads to a steady initial decrease in $\sigma_{G}$, as the estimation of gradient becomes more robust. However, as more data are included from shallower depths (where non-linear features are present) this tendency is reversed and $\sigma_{G}$ increases. In the present work, the depth corresponding to the minimum value of $\sigma_{G}$ is considered as indicative of the top of the unperturbed zone. The background gradient determined for the depth interval below this zone is used for calculating the steady component of the temperature field. Subtracting it from the 
observed temperatures allows determination of the transient component. A similar procedure has also been employed by Roy et al. (2002) in the separation of steady and transient components of temperature profiles in the Indian subcontinent.

In the inverse problem approach (Tarantola and Valette, 1982) a priori information is explicitly incorporated in constraining the solution. The functional space inversion (FSI) method discussed by Shen and Beck $(1991,1992)$ and Shen et al. (1992) makes use of the non-linear least squares theory in solving the one dimensional heat conduction equation in a layered half space. The algorithm employed finds the model that minimizes the misfit function:

$$
\begin{aligned}
S(m)= & \frac{1}{2}\left\{\left[\left(d-d_{0}\right)^{t} C_{d}^{-1}\left(d-d_{0}\right)\right]+\right. \\
& {\left.\left[\left(m-m_{0}\right)^{t} C_{m}^{-1}\left(m-m_{0}\right)\right]\right\} }
\end{aligned}
$$

where $\mathrm{d}$ and $\mathrm{d}_{0}$ are respectively the calculated and observed temperatures, $\mathrm{m}$ and $\mathrm{m}_{0}$ the calculated and a priori model parameters and $\mathrm{C}_{d}$ and $\mathrm{C}_{m}$ the covariance matrices of $\mathrm{d}_{0}$ and $\mathrm{m}_{0} . \mathrm{C}_{d}$ indicates the uncertainty in the observed temperature-depth data while $\mathrm{C}_{m}$ indicates uncertainty in the a priori model. The selection of appropriate values of a priori standard deviations for the temperature $\left(\sigma_{d 0}\right)$ and thermal conductivity $\left(\sigma_{k 0}\right)$ data are important in determining the solutions.

The main advantage of FSI formulation is that it does not predetermine the steady state temperature profile. Instead, both the steady state and transient profiles are estimated simultaneously. In addition, it allows consideration of the vertical distribution of thermo-physical properties and their uncertainties as model parameters, allowing thereby determination of a more detailed GST history where it is possible to identify second order features. Also, FSI formulation includes as model parameters all variables that govern the conductive thermal regime (background heat flow density, the GST history as a function of time and thermal properties as functions of depth).

\section{Estimates of surface temperature changes}

The vertical distributions of temperatures in boreholes that have passed the selection criteria are illustrated in Fig. 2. In this figure some of the temperature-depth profiles have been shifted laterally to convenient positions along the temperature axis, to avoid overlap and to allow for easy visualization. Consequently, the temperature axis in Fig. 2 displays only relative values.

The vertical distributions of temperatures in Fig. 2 reveal several remarkable features. For example, the shapes of the temperature depth profiles at shallow depths are consistently concave towards the depth axis, indicative of surface warming events of relatively recent times. The widespread occurrence of such temperature-depth profiles in almost all of the

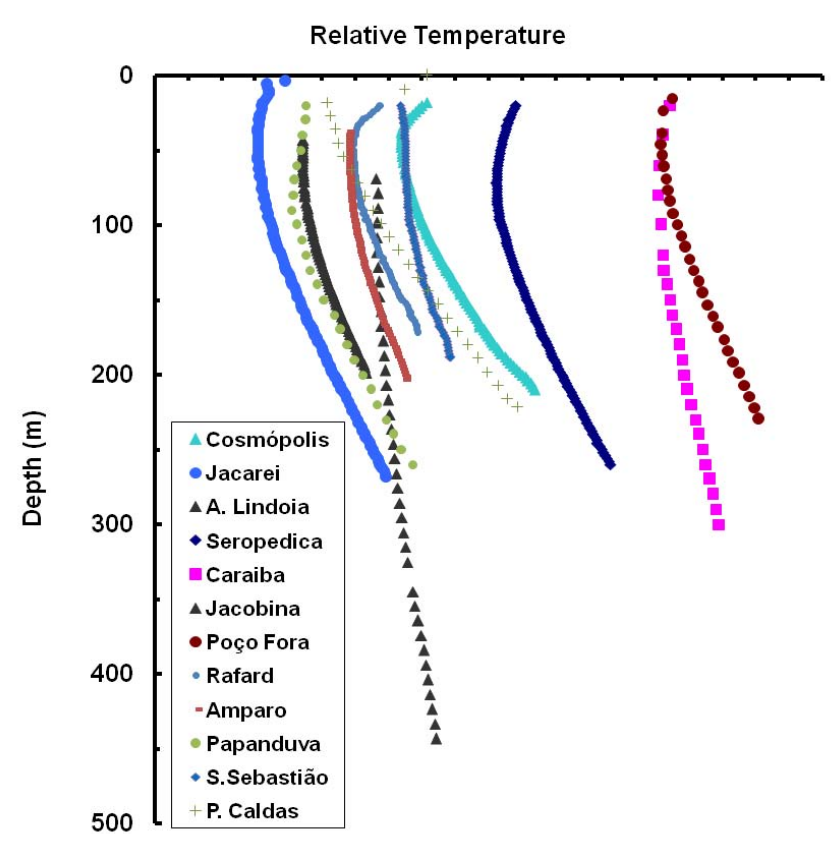

Fig. 2. Temperature-depth profiles of boreholes situated in the southeastern parts of Brazil. For the sake of clarity in presentation only selected data sets are included. In addition, some of the temperature-depth profiles are shifted to convenient positions to avoid overlap. Consequently, the temperature axis display only relative values.

major geographic zones, irrespective of the local geological complexities and changes in soil type, is considered a clear indication that the observed features are not related to local processes but generated by a surface warming event of large spatial dimensions. In this context, it is significant that temperature profiles with shapes that are convex towards the depth axis, and hence characteristic of cooling events, were not encountered.

\subsection{Forward model results}

The vertical distributions of transient components derived from forward model results are illustrated in Fig. 3. Note that the magnitudes of the transient components decrease rapidly with depth. At depths greater than 150 meters these values fall below the experimental detection limits of temperature changes in boreholes. The period of GST change fall in the range of 130 to 260 years. Hence the beginning of the climate change seems to have taken place during the period of approximately 1750 to 1850 . A closer examination of the results illustrated in Fig. 3 reveals some marked differences in the GST values within individual geographic zones. The primary reason for the occurrence of such intra-zonal variations is unknown at the moment, but it is likely that they are related to microclimatic histories of individual sites. Also, the depth distribution of the transient components indicates that the magnitude of warming event is relatively smaller (in 
Table 2. Results of Ramp Inversions for surface temperature changes, for localities in eastern Brazil. $\Gamma$ is the local geothermal gradient, $\mathrm{T}_{0}$ the intercept of linear fit, $\Delta \mathrm{T}$ the magnitude of ramp change, and $\mathrm{r}$ the root mean square misfit. The climate zones of the localities are indicated by asterisk marks. (* - Subtropical high land; **-Subtropical humid; *** - Semi-arid)

\begin{tabular}{|c|c|c|c|c|c|c|}
\hline \multirow{2}{*}{ Locality } & \multirow{2}{*}{$\Gamma\left({ }^{\circ} \mathrm{C} / \mathrm{km}\right)$} & \multirow{2}{*}{$\mathrm{T}_{0}\left({ }^{\circ} \mathrm{C}\right)$} & \multirow{2}{*}{$\Delta \mathrm{T}\left({ }^{\circ} \mathrm{C}\right)$} & \multicolumn{2}{|c|}{ Time (year) } & \multirow{2}{*}{$\mathrm{r}(\mathrm{mK}$} \\
\hline & & & & Duration & Onset & \\
\hline Águas Lindóia* & 19.9 & 18.4 & 3.2 & 105 & 1877 & 4.4 \\
\hline Amparo* & 18.3 & 18.8 & 2.8 & 115 & 1852 & 5.5 \\
\hline Cosmópolis* & 28.8 & 20.0 & 3.8 & 75 & 1907 & 5.5 \\
\hline Jacarei* & 22.6 & 19.9 & 3.0 & 125 & 1861 & 2.8 \\
\hline Rafard* & 23.4 & 18.9 & 3.8 & 60 & 1922 & 6.8 \\
\hline Itu* & 18.5 & 19.6 & 1.2 & 60 & 1922 & 3.2 \\
\hline Jundiaí* & 20.2 & 18.7 & 1.2 & 50 & 1932 & 7.2 \\
\hline Serra Negra* & 24.2 & 18.3 & 2.0 & 105 & 1877 & 3.9 \\
\hline Poços Caldas* & 33.4 & 18.2 & 2.0 & 50 & 1926 & 13.7 \\
\hline Papanduva** & 22.9 & 16.8 & 3.2 & 90 & 1885 & 25.0 \\
\hline Seropédica** & 22.4 & 21.8 & 3.8 & 145 & 1860 & 23.1 \\
\hline São Sebastião** & 14.3 & 21.2 & 1.6 & 70 & 1920 & 23.1 \\
\hline Jacobina*** & 7.0 & 20.4 & 1,4 & 85 & 1890 & 8,4 \\
\hline Arraial*** & 12.4 & 27.6 & 1,4 & 85 & 1890 & 8,4 \\
\hline Caraiba-1*** & 14.9 & 28.9 & 1,4 & 110 & 1865 & 9,3 \\
\hline Caraiba- $2 * * *$ & 10.1 & 28.9 & 2,0 & 125 & 1850 & 8,4 \\
\hline Poço Fora*** & 19.5 & 28.6 & 2,2 & 105 & 1870 & 4,9 \\
\hline
\end{tabular}

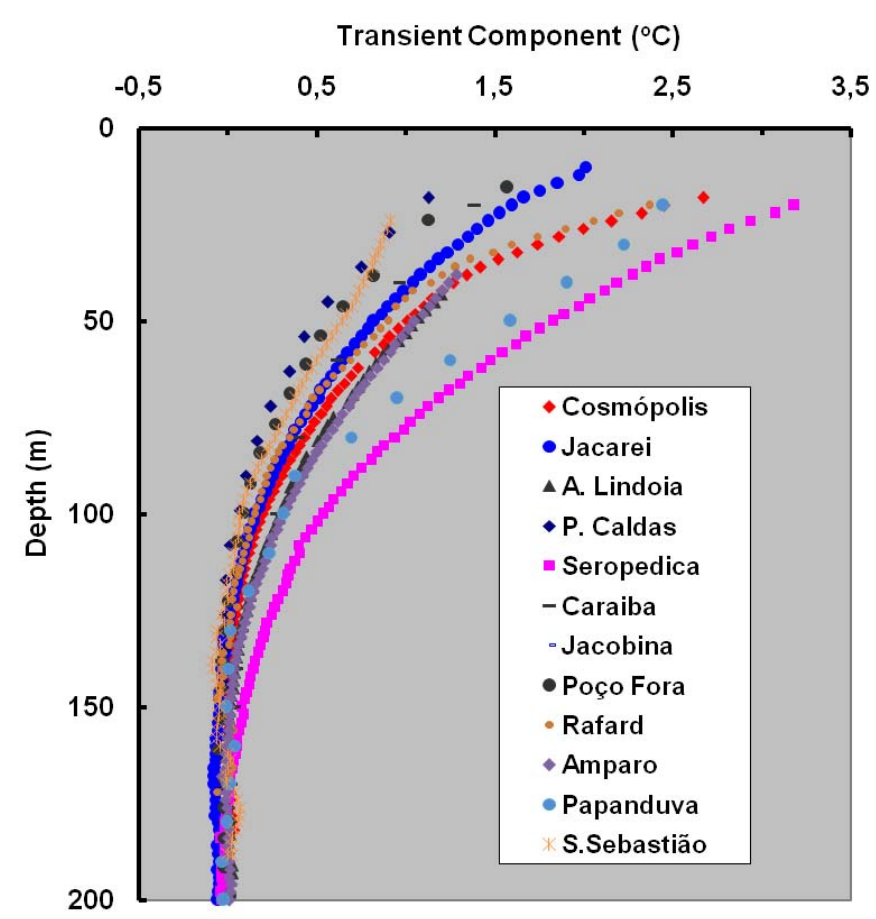

Fig. 3. Vertical distributions of transient components of subsurface temperatures in boreholes located in eastern parts of Brazil. Note that only selected data sets were included, for the sake of clarity in presentation. the range of 1.4 to $2.2^{\circ} \mathrm{C}$ ) for the semi-arid zone in northeastern parts of Brazil. The close agreement between the results for the three localities is considered as indication that local changes in vegetation cover and soil types have only a minor influence on the surface thermal budget in semi-arid zones. The GST change in this region seems to have had its beginning during the time period of 1850 to 1900 , significantly earlier than the corresponding periods for other geographic zones.

A careful examination of Fig. 3 reveals that some of the transient temperature profiles do have small negative values for depth intervals corresponding to the bottom parts of the transient sections. The negative residuals are usually considered as arising from cooling events prior to recent warming episodes. However, the magnitudes of such events appear as subdued features, because of the implicit assumption that the bottom parts of the borehole are free of transient perturbations. Results of numerical simulations indicate that occurrence of negative residuals is quite sensitive to subtle changes in the value adopted for the background temperature gradient. This is the main limitation of the forward model approach, which resolves mainly for the first-order features in the GST history. We conclude by noting that residual temperature profiles similar to those obtained in the present work were also reported by Golovanova et al. (2001) for the Urals region and Roy et al. (2002) for the Indian Peninsula. A complementary analysis of this problem is provided in Sect. 5.2, where we discuss the residual temperature profiles derived using the inversion method. 
A summary of the results obtained in fitting the forward models to the observational data discussed in this work, is presented in Table 2. It includes magnitudes of the GST change $(\Delta T)$ and their duration $(t)$ as well as the values of the rms misfit between the model and the observational data. For reasons of brevity, we present here only the results for the ramp function model. Also given in Table 2 are the values of the local geothermal gradient $(\Gamma)$ and the extrapolated surface temperature $\left(\mathrm{T}_{0}\right)$, calculated on the basis of linear fit to the bottom section of the temperature-depth profiles. As before, the results are grouped together for the three major geographic zones.

The results of Table 2 reveal distinct differences in the values of mean GST changes between the major geographic zones. For example, the subtropical highland areas seem to be characterized by changes in GST in the range of 1 to $3.5^{\circ} \mathrm{C}$. The subtropical humid zones of the interior and coastal regions also seem to have nearly similar GST changes. On the other hand, the semiarid zones in the northeast are characterized by relatively low GST changes, in the interval of 1 to $2^{\circ} \mathrm{C}$.

\subsection{Results of functional space inversion}

As prelude to the presentation of the results obtained by the functional space inversion method we provide brief descriptions of the steps taken in data processing and analysis. These include specifying the depth intervals and time periods used for inversion, setting a priori standard deviations of temperature and thermal conductivity data sets and measures taken to minimize the undesirable consequences of the null hypothesis in the inversion scheme.

The estimates of the depth at which the thermal regime is supposedly untouched by the GST variations and the time limit beyond which GST variations cannot be recovered from the given temperature log data were chosen in accordance with the depth extent of the available temperature log data. In particular, the depth estimate is set to be greater than the deepest data point because the calculated data are projected (interpolated) from the finite element solution. As for the time limit there is no harm in setting a value compatible with or greater than the depth extent of the borehole (Shen and Beck, 1992). On the other hand, use of a shorter-thannecessary time span would end up in "telescoping" the GST history. Unless there are independent evidences indicating a rapid return to unperturbed conditions it seems prudent to assume that this return take place gradually. The influence of setting different values for the time span is illustrated in Fig. 4, for temperature profile of $443 \mathrm{~m}$ deep borehole in Jacobina (Bahia). Note that use of shorter time spans leads to slight reductions in the magnitude and duration of the cooling events of the earlier periods.

As pointed out by Shen and Beck $(1991,1992)$ the results of ground surface temperature (GST) history, determined by functional space inversion, is sensitive to a priori standard de-

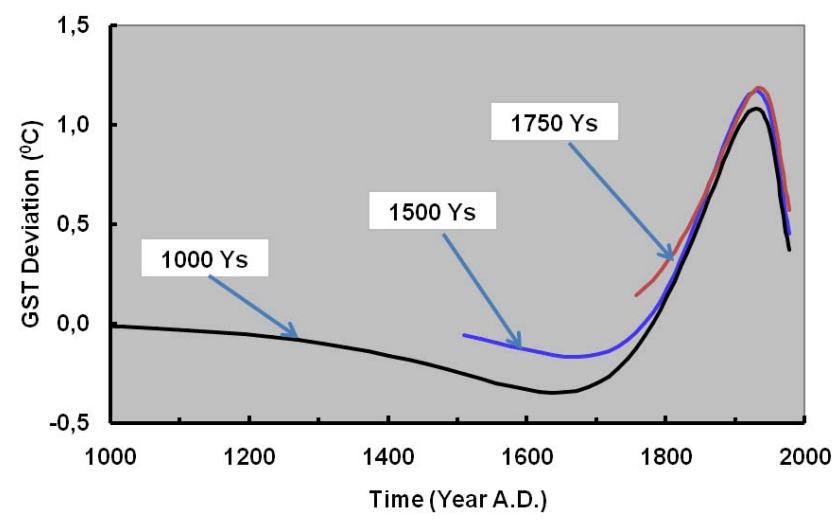

Fig. 4. Illustration of the effect of setting different time spans in FSI implementation for deducing GST history. The example is based on inversion of temperature-depth data for $443 \mathrm{~m}$ deep borehole in Jacobina (Bahia). Note that use of shorter time spans leads to slight reductions in the magnitude and duration of the cooling events of the earlier periods.

viations of thermal conductivity. The preferred values for the standard deviations are based on considerations of the tradeoff between consistency of the solution and data resolution. In the present work we have used $50 \mathrm{mK}$ for standard deviation of the temperature data $\left(\sigma_{d 0}\right)$ and $1 \mathrm{~W} / \mathrm{mK}$ for standard deviation of the thermal conductivity $\left(\sigma_{k 0}\right)$. These values are of the same order of magnitude as those adopted by Safanda and Rajver (2001) and Golovanova et al. (2001).

FSI inversion makes use of an a priori null hypothesis in obtaining robust estimates of the prior steady state (Shen et al., 1996). However, it is convenient to note that this built-in feature can potentially lead to undesirable results when inversions are attempted for determining GST history of periods not correlated with the subsurface temperature data. Thus, in the absence of suitable temperature data for shallow depths the inversion scheme generates artificial values for the late part of GST history, as part of the computational procedure. As an illustrative example we compare in Fig. 5 inversion results for the site Seropedica (state of Rio de Janeiro), with and without considering temperature data for shallow depths. In this figure, curve 1 refers to the case in which all data from the depth range of 20 to $262 \mathrm{~m}$ are included in the inversion scheme. The remaining three curves labeled 2, 3 and 4 refer to cases where data from depths less than 50,100 and $150 \mathrm{~m}$ are progressively excluded from the inversion scheme. Note that in these cases $(2,3$ and 4$)$ the inversion has generated artificial cooling episodes for the later part of the GST history. Cases 1 and 2 are almost indistinguishable, while in case 3 the spurious cooling event begins during the decade of 1970. For curve 4 the cooling event begins during the decade of 1940. It is clear that acquisition of reliable temperature data for shallow depths is important in determining GST history of the last few decades. On the other hand, the results also show that occurrence of artificial cooling trends for the 


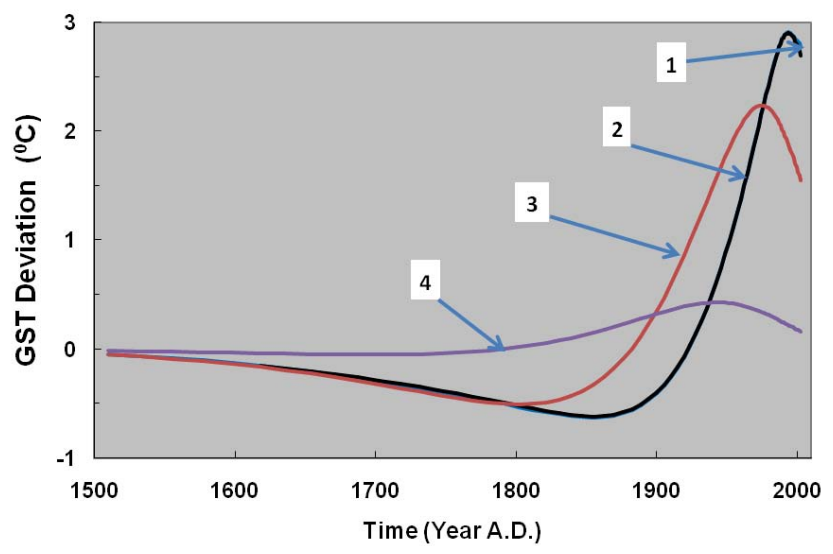

Fig. 5. Illustration of the potential effect of null hypothesis in the inversion scheme for data set from Seropedica (Rio de Janeiro). Curve 1 refers to the case in which all data, for the depth range of 20 to $262 \mathrm{~m}$, are included in the inversion scheme. The remaining three curves, labeled 2, 3 and 4, refer to cases where data from depths less than 50,100 and $150 \mathrm{~m}$ are progressively excluded from the inversion scheme. Note that in these cases (2, 3 and 4) the inversion has generated artificial cooling episodes for the later part of the GST history. See text for more details.

decades prior to 1970 are possible only in cases where temperature measurements are restricted to depths greater than $100 \mathrm{~m}$.

In the present work temperature data are available for depths less than 50 meters in all of the data sets employed in inversion schemes. Consequently we conclude that cooling trends observed in our results, for the decades prior to 1970, cannot be attributed to the spurious effects of the null hypothesis. In addition, potential undesirable effects of the null hypothesis are minimized by limiting the GST history to periods compatible with reliable subsurface temperature data. Examples of cooling trends similar to those found in the present work can also be seen in the results reported for several localities in Europe and North America (Bodri and Cermak, 1995; Gosnold et al., 1997; Rajver et al., 1998; Stulc et al., 1998; Golovanova et al., 2001). Functional space inversion method was employed in analysis of temperaturedepth profiles for 14 localities distributed over the three main geographic zones of Brazil. The criteria used in the selection of profiles included availability of both thermal property data of subsurface layers and supplementary information on the history of changes in the vegetation cover. The vertical distributions of transient components derived from FSI inversions are illustrated in Fig. 6. It reveals several characteristic features in the GST changes in the study area. To begin with we note that the magnitudes of the transient components decrease rapidly with depth, indicating the occurrence of significant surface warming events during the last century. However, the residual temperatures become significantly negative at depth intervals corresponding to the bottom parts of

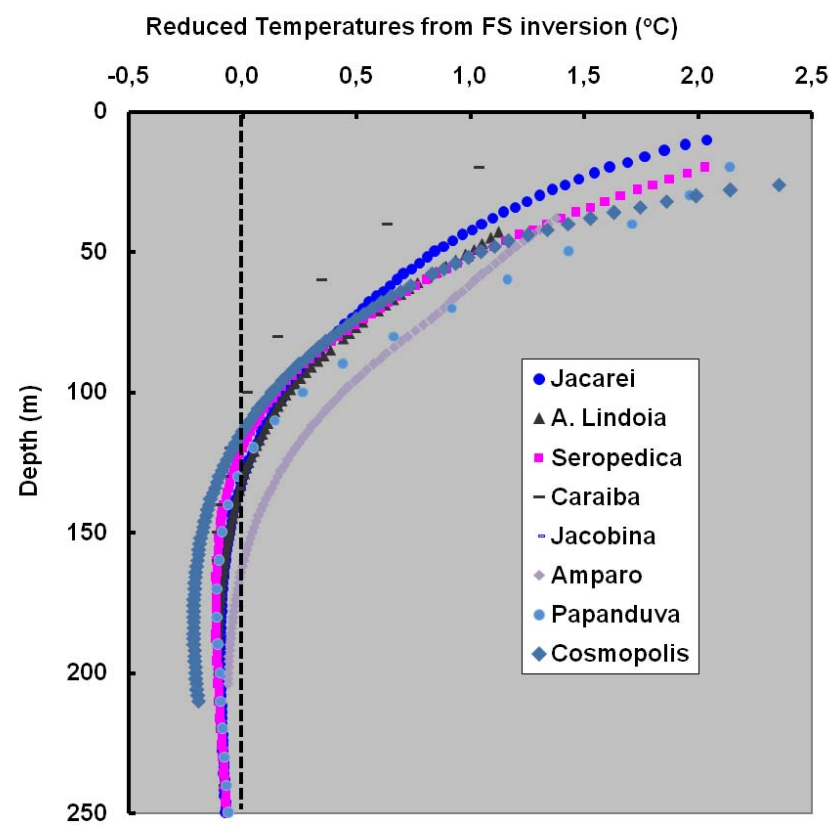

Fig. 6. Vertical distributions of transient components of subsurface temperatures in boreholes located in eastern parts of Brazil, derived using functional space inversion method. Note the presence of negative residuals in the bottom parts of boreholes, indicative of cooling episodes of the 17th and 18th centuries. Only selected data sets were included, for the sake of clarity in presentation.

the transient sections. Such negative residuals are indicative of the occurrence of cooling events prior to recent warming episodes. At this point it is important to point out that both the magnitudes of negative residuals and the depth intervals over which they occur are significantly different from the results of the forward model approach (see Fig. 3). Since the FSI method is relatively more successful in extracting information on second order features in deeper section of borehole temperature profiles we conclude that the vertical distributions of residual temperatures in Fig. 6 are better representations of subsurface transient thermal regimes than those derived from the forward model approach.

The FSI method also provides more detailed information on the GST history than that provided by the forward model approach. However, in comparing the GST histories of several localities it is convenient to work with deviations from the site specific mean rather than the absolute value. In the present work, GST deviations are calculated by subtracting the model results from the a posteriori estimate of the site specific mean. The results illustrated in Fig. 7, reveal several characteristic features in the GST history of the study area. The ground surface temperatures of the localities considered have increased by as much as 1 to $4^{\circ} \mathrm{C}$, over the last century. This observation is in reasonable agreement with the results of the ramp function model discussed in the previous section. However, in all localities the warming events seem 
Table 3. Results of functional space inversion for selected data sets. Maximum and minimum values of GST and their respective years of occurrences are given in columns 3-6. Also given are the differences between the maximum and minimum (D) and the time elapsed between the maximum and minimum $(\mathrm{t}) . \mathrm{T}_{0}$ is the a posteriori steady state temperature.

\begin{tabular}{lllllllll}
\hline \multirow{2}{*}{ Climate Province } & Locality & \multicolumn{2}{c}{ Maximum } & \multicolumn{2}{c}{ Minimum } & \multicolumn{2}{c}{ Difference } & \multirow{2}{*}{$\mathrm{T}_{0}\left({ }^{\circ} \mathrm{C}\right)$} \\
& & ${ }^{\circ} \mathrm{C}$ & $\mathrm{Yr}$ & ${ }^{\circ} \mathrm{C}$ & $\mathrm{Yr}$ & $\mathrm{D}\left({ }^{\circ} \mathrm{C}\right)$ & $\mathrm{t}(\mathrm{yr})$ & \\
\hline & Aguas Lindoia & 20.8 & 1964 & 18.2 & 1850 & 2.6 & 175 & 18.7 \\
& Amparo & 21.1 & 1952 & 18.1 & 1781 & 3.0 & 171 & 18.7 \\
& Cosmópolis & 24.5 & 1985 & 18.2 & 1802 & 6.3 & 183 & 19.4 \\
Subtropical Highlands & Jacarei & 22.8 & 1986 & 19.5 & 1802 & 3.3 & 184 & 20.1 \\
& Itu & 22.6 & 1986 & 17.5 & 1855 & 1,3 & 131 & 18.5 \\
& Jundiai & 21.7 & 1984 & 17.6 & 1820 & 4.1 & 164 & 18.3 \\
& Serra Negra & 20.2 & 1984 & 17.6 & 1781 & 2.6 & 203 & 18.0 \\
& & & & & & & & \\
Interior and Coastal & Papanduva & 20.5 & 1962 & 16.2 & 1831 & 4.3 & 131 & 17.0 \\
& Seropédica & 25.3 & 1992 & 21.8 & 1849 & 3.5 & 143 & 22.5 \\
& & & & & & & & \\
Semiarid Zones & Jacobina & 21.9 & 1928 & 20.6 & 1672 & 1.3 & 256 & 20.7 \\
& Arraial & 28.8 & 1967 & 27.2 & 1863 & 1.6 & 104 & 27.7 \\
& Caraiba-1 & 30.1 & 1949 & 28.6 & 1792 & 1.5 & 157 & 28.9 \\
& Caraíba-2 & 30.8 & 1973 & 28.7 & 1822 & 2.1 & 151 & 29.2 \\
& Poço Fora & 30.4 & 1973 & 28.2 & 1821 & 2.2 & 152 & 28.7 \\
\hline
\end{tabular}

to be preceded by cooling episodes occurring over the time period of approximately 1700 to 1900 . The amplitudes of the cooling events are much less, falling generally in the range of 0.5 to $1^{\circ} \mathrm{C}$. Under the current limitations in sensitivity and precision of sensors used for temperature measurements in boreholes, the resolving power of the inversion method is poor for time periods prior to the 17th century. Hence the model calculations for periods prior to 1700 may not necessarily be representative of true climate history.

Results of Fig. 7 also reveal that the warming event in the highlands region had its beginning during the time period of 1850 to 1900 . On the other hand, the warming event in semiarid regions seems to have had its beginning during the period of 1670 to 1860 . Also the durations of both warming and cooling episodes appear to be relatively smaller in highland regions relative to those for the semi-arid regions. Such differences have important implications for understanding evolutionary trends in climate history of eastern Brazil. The uncertainties in the estimates of GST in the inversion method can somewhat be improved by carrying out simultaneous inversion of temperature profiles of several sites in the same geographical province. In the present work we have carried out simultaneous inversions only for repeat measurements at Seropédica, in the state of Rio de Janeiro. In view of notable differences in the local soil conditions and vegetation cover, no attempt has been made for carrying out simultaneous inversions of temperature profiles from different locations discussed in the present work. Also, most of these sites are separated by large distances and fall within areas with distinctly different microclimate conditions and geographic characteristics.

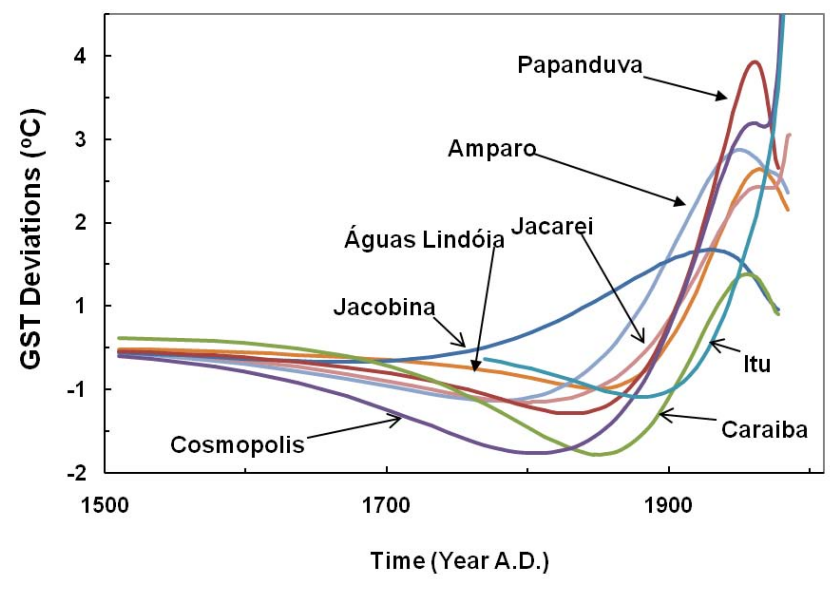

Fig. 7. Transient ground surface temperature changes derived from inverse models of temperature-depth profiles for selected localities in southeast Brazil.

A summary of the results of inverse modeling is presented in Table 3. The summary includes maximum and minimum values of ground surface temperatures and their respective times of occurrence. Also given in this table are the difference between the maximum and minimum values of GST, the time elapsed between the maximum and minimum and a posteriori estimates of undisturbed GST. 
Table 4. Summary of long term trends in air and soil temperature records. $\mathrm{N}$ is number of data.

\begin{tabular}{lllll}
\hline Locality & Period & Data Type & $\mathrm{N}$ & Trend $\left({ }^{\circ} \mathrm{C} / \mathrm{yr}\right)$ \\
\hline Rio de Janeiro & $1857-1866$ & $\begin{array}{l}\text { Surface air } \\
\text { temperature }\end{array}$ & 85 & -0.017 \\
Curitiba & $1885-1909$ & $\begin{array}{l}\text { Surface air } \\
\text { temperature }\end{array}$ & 289 & -0.004 \\
São Paulo & $1965-1990$ & $\begin{array}{l}\text { Soil } \\
\text { temperature }\end{array}$ & 294 & +0.017 \\
\hline
\end{tabular}

\section{Comparison with surface air temperature records}

The availability of surface air temperature records of the last century at some of the meteorological stations in Southern Brazil provide an opportunity for an independent check on the history of GST changes inferred from borehole data. There are however several problems in analysis of meteorological records, especially those for the period prior to 1950. Frequent changes in the characteristics of temperature sensors and data acquisition procedures have made it difficult to obtain reasonably long time series with consistent quality characteristics that can be employed in comparative studies. In the present work, we have identified three time series that satisfy the required criteria:

1. Air temperature records for the city of Rio de Janeiro for the period of 1857 to 1866 ;

2. Air temperature records for the city of Curitiba for the period of 1885 to 1909 ;

3. Soil temperatures at $40 \mathrm{~cm}$ depth at the Meteorological Observatory of São Paulo, for the period of 1965 to 1990 .

A preliminary analysis of these data sets was carried out by Hamza (1998). We reproduce here only the results relevant for comparative analysis of GST variations deduced from borehole data. Examination of air temperature records reveal that the short period fluctuations arising from seasonal variations have a dominating influence. In an attempt to minimize this problem seasonally adjusted air temperatures were calculated for data available in the primary records for Rio de Janeiro and Curitiba. The long term variations determined from these data sets indicate cooling trends of $1.7^{\circ} \mathrm{C} /$ century for the period of 1857 to 1866 in Rio de Janeiro and $0.4^{\circ} \mathrm{C} /$ century for the period of 1885 to 1909 in Curitiba. The periods of such cooling trends are in reasonable agreement with those determined from inversion models. The soil temperatures recorded by the meteorological observatory of the University of São Paulo provides a slightly different picture. To begin with, most of very short period variations are sharply attenuated, since measurements were made $40 \mathrm{~cm}$ depth. In taking advantage of this feature, monthly means of soil temperatures were calculated for the period 1965 to 1990. To extract the long term climatic trend the data were fit to a function of the type:

$$
\begin{aligned}
T(t)= & a+b t+c \cos \left(2 \pi t / P_{a}\right)+d \sin \left(2 \pi t / P_{a}\right)+ \\
& e \cos \left(2 \pi t / P_{S 1}\right)+f \sin \left(2 \pi t / P_{S 1}\right)+ \\
& g \cos \left(2 \pi t / P_{S 2}\right)+h \sin \left(2 \pi t / P_{S 2}\right)
\end{aligned}
$$

where $T$ is temperature, $t$ the time, $a$ the mean annual temperature, $b$ the long term climatic trend, $P a$ the annual cycle with period of 12 months and $\mathrm{P}_{S 1}$ and $\mathrm{P}_{S 2}$ are solar cycles with periods of 11 and 22 years respectively. The least squares fit of Function (3) to the observed data using the SVD (Singular Value Decomposition) method of Press et al. (1986) resulted in the following relation:

$$
\begin{aligned}
T(t)= & (21.47 \pm 0.12)+(0.00114 \pm 0.00045) t+ \\
& (2.457 \pm 0.007) \cos \left(2 \pi t / P_{a}\right)+(2.186 \pm 0.087) \\
& \left.\sin \left(2 \pi t / P_{a}\right)+0.970 \pm 0.850\right) \sin \left(2 \pi t / P_{S 1}\right)
\end{aligned}
$$

The coefficients $\mathrm{e}, \mathrm{g}$ and $\mathrm{h}$ were not included in the final representation since the errors associated with their estimates are large compared with their magnitudes. The multiple correlation coefficient for the fit is 0.91 while the partial correlation coefficient for $\mathrm{b}$ is 0.0998 . The significance level $\left(\mathrm{S}_{L}\right)$ of this value evaluated using the relation:

$S_{L}=\operatorname{erfc}[r / \sqrt{(N / 2)}]$

was found to be 0.09 . The non-periodic residuals determined in this manner point to a long term warming trend of $1.7^{\circ} \mathrm{C} /$ century, for the time period 1965 to 1990 . A summary of long term trends in air and soil temperature records is provided in Table 4 . The cooling and warming trends inferred from meteorological records are in reasonable agreement with the first order features in GST history illustrated in Fig. 7.

At this point it is convenient to point out that the sites for which suitable meteorological records exist are located in or close to the major urban centers in Brazil. Lack of longterm meteorological records at localities close to the sites for which subsurface temperature data are available has been a major obstacle in carrying out integrated studies of GST and SAT data sets. On the other hand SAT data of the last few decades are currently available for a large number of municipalities and smaller towns in eastern Brazil. Efforts are currently under way for collecting such data, for eventual use as a priori information in inversion studies.

\section{Discussion and conclusions}

The results obtained in the present work indicate that surface temperatures have increased during the last century in most of the major geographic zones of eastern Brazil. Magnitudes of the GST changes are in the range of 1 to $4^{\circ} \mathrm{C}$ while 


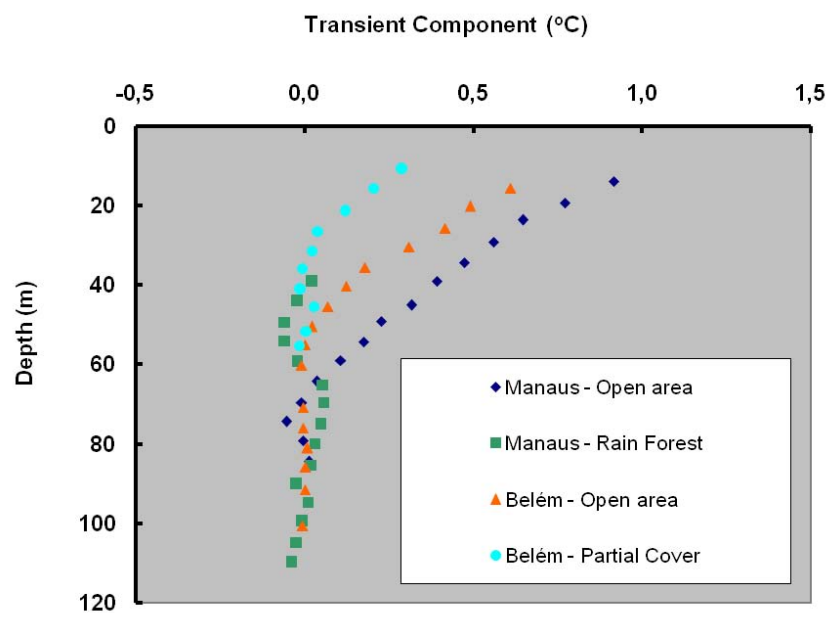

Fig. 8. Vertical distributions of residual temperatures in shallow boreholes, located at sites close to urban areas of Belém and Manaus, in the northern Amazon region of Brazil.

their durations are found to fall in the interval of 100 to 200 years. The occurrence of such changes in regions of large area extent and of differing vegetation cover imposes severe constraints on the possible mechanisms involved. Another notable feature of GST variations in Brazil is that the recent warming trend is preceded by a cooling episode with magnitudes of less than $1{ }^{\circ} \mathrm{C}$, during the 17th and 18th centuries. Similar cooling episodes have also been identified in several regions of Europe and North America (e.g. Golovanova et al, 2001; Safanda and Rajver, 2001; Majorowicz and Safanda, 2001).

There is very little information at present on GST changes for the northern tropical region of Brazil. Souza et al. (1991) reported results of temperature logs of three shallow bore holes in the city of Belém (northern State of Pará) and three more in Manaus (state of Amazon). Detailed analysis of GST history for these localities is not attempted here, the data sets being not fully compatible with the depth criteria adopted in the present work. However, residual temperatures calculated for four boreholes, presented in Fig. 8, reveal that nonlinear features in temperature logs are relatively small or altogether absent at shallow depths of less than 150meters. We consider this observation as indication that GST changes are much subdued in tropical regions with thick vegetation cover, such as rain forests. The emerging conclusion is that subsurface temperatures in tropical forest areas are likely to be less prone to climate changes. The role of vegetation cover in controlling GST changes has also been noticed in the earlier works by Lewis and Wang (1988), Taniguchi et al. (1999a, b) and Rimi (2000). A similar conclusion was also reached by Cerrone and Hamza (2003) in comparing contour maps of GST changes in southeast Brazil with satellite images of vegetation cover for the state of Rio de Janeiro.

In summary, it appears that the observed subsurface tem-

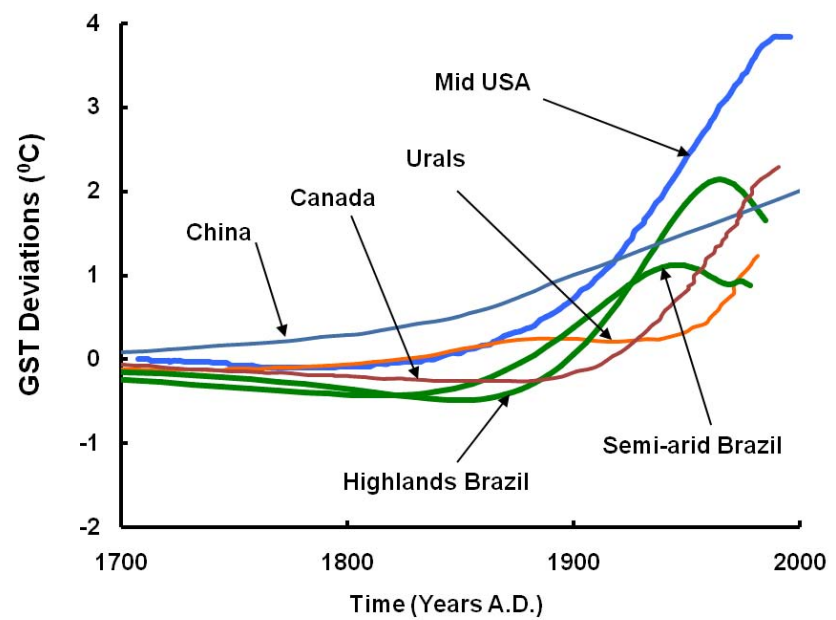

Fig. 9. Comparison of GST deviations observed in typical climate provinces in Brazil with those reported for selected localities in Mid-continent USA (Gosnold et al., 1997), Western Canada (Majorowicz and Safanda, 2001), Southwest China (Huang et al., 1995) and the Urals (Golovanova et al., 2001). Note that all regions are characterized by pronounced warming trends in GST during the last century, but the localities in Brazil reveal a small cooling trend for the period of approximately 1750 to 1900 .

perature variations in semi-arid regions and tropical rain forests represent extreme or end-member cases of large scale GST changes in the study area. The observed GST changes in the subtropical regions in the southern and southeastern parts of Brazil represent intermediate cases which include components related to changes in both global climate and local vegetation cover.

Lack of reliable data for the central and northern parts is a limitation in understanding the geographic distribution of GST changes in continental area of Brazil. Nevertheless, the present data set has been employed in deriving mosaic and contour representations of regional trends in recent GST changes for areas of low data density. The results reveal that GST changes are prominent in the southern and southeastern parts and moderate in the northeastern region.

Finally a brief comment of the similarities and differences between GST changes observed in Brazil with those reported for other continental regions is in order. The GST changes reported for USA (Gosnold et al., 1997), western Canada (Majorowicz and Safanda, 2001), Southwest China (Huang et al., 1995; and Urals (Golovanova et al., 2001) were selected for this purpose. A simple comparison of GST changes reported for these regions with those observed for Brazil is illustrated in Fig. 9. Note that the warming trend of the last century observed for most localities in Brazil are similar to the GST changes reported for corresponding periods in the northern hemisphere. However, for the period of 1700 to 1900 , the observed GST variations in Brazil seem to have systematically lower magnitudes than those reported for other continental areas. 
Acknowledgements. The second author of this paper has been recipient of a scholarship granted by Fundação Amparo á Pesquisa do Estado do Rio de Janeiro - FAPERJ, during the period 20012003. The soil temperature data reported in the present work was furnished by the meteorological observatory of the University of São Paulo. The source code for functional space inversion program was provided by P. Shen, University of Western Ontario, Canada. We thank the Topic Editor and the Reviewers of this special issue for their critical comments and suggestions and I. Escobar of the National Observatory (ON-MCT, Rio de Janeiro) for fruitful discussions on problems of climate change in Brazil. The present work did not receive financial support from funding organizations in Brazil.

Edited by: J. Smerdon

\section{References}

Appleyard, S. J.: Late Holocene temperature record from southwestern Australia: evidence of global warming from deep boreholes, Australian J. Earth Sci., 52, 161-166, 2005.

Araújo, R. L. C.: Heat flow measurements in the Alkaline intrusive complex of Poços de Caldas (in Portuguese). Unpublished M.Sc. Thesis, University of São Paulo, São Paulo, Brazil, 1978.

Beltrami, H., Jessop, A. M., and Mareschal, J. C.: Ground temperature histories in eastern and central Canada from Geothermal measurements: Evidence of climatic change, Palaeogeogr. Palaeoclimatol. Pallaeoecol., 98, 167-184, 1992.

Beltrami, H. and Bourlon, E.: Ground warming patterns in the Northern Hemisphere during the past five centuries, Earth Plnet. Sci. Lett., 227, 169-177, 2004.

Birch, F.: The effects of Pleistocene climatic variations upon geothermal gradients, Am. J. Sci., 246, 729-760, 1948.

Bodri, L. and Cermak, V.: Climate changes of the last millennium inferred from borehole temperatures: results from the Czech Republic - Part I, Global and Planetary Change, 11, 111-125, 1995.

Carslaw, H. S. and Jaeger, J. C.: Conduction of Heat in Solids, 386pp, Oxford University Press, New York, 1959.

Cavalcanti, A. S. B.: Palaeoclimate variations in Brazil based on the geothermal method (in Portuguese), Unpublished M.Sc. Thesis, Observatório Nacional, Rio de Janeiro, Brazil, 2003.

Cavalcanti, A. S. B. and Hamza, V. M., Climate changes of the recent past in southern parts of Brazil (Extended abstract), 7th International Congress of the Brazilian Geophysical Society, Salvador (BA), Brazil, 1-4, 2001.

Cermak, V.: Underground temperature and inferred climatic temperature of the past millennium, Palaeogrogr., Palaeoclimatol., Palaeoecol., 10, 1-19, 1971.

Cerrone, B. N. and Hamza, V. M.: Climate changes of the recent past in the state of Rio de Janeiro, based on the geothermal method (Extended abstract in Portuguese), 8th International Congress of the Brazilian Geophysical Society - SBGf, Rio de Janeiro, Brazil, 1-4, 2003.

Chisholm, T. J. and Chapman, D. S.: Climate change inferred from analysis of borehole temperatures: an example from western Utah, J. Geophys. Res., 97, 14 155-14 175, 1992.

Conceição, E. and Hamza, V. M.: Subsurface thermal signals of the greenhouse effect in the state of São Paulo (Extended Abstract in
Portuguese), 2nd International Symposium of the Brazilian Geophysical Society - SBGf, Natal (RN), Brazil, 1-6, 2006.

Cull, J. P.: Climatic corrections to Australian heat flow data. BMR Journal of Australian Geology and Geophysics, 4, 303-307, 1979.

Cull, J. P.: Geothermal records of climate change in New South Wales, Search, 11(6), 201-203, 1980.

Del Rey, A. C.: Hydrogeothermal studies of the regions of Águas de Lindoia, Amparo e Socorro - Northeastern parts of the state of São Paulo (in Portuguese), Unpublished M.Sc. Thesis, University of São Paulo, São Paulo, Brazil, 1989.

Del rey, A. C. and Hamza, V. M.: Terrestrial heat flow variations in the northeastern part of the state of São Paulo: A case for transport of geothermal heat by inter-fracture fluid flows, in: Hydrogeological regimes and their subsurface thermal effects, edited by: Beck, A. E., Garven, G. and Stegena, L., Geophysical Monograph, 47, IUGG volume 2, American Geophysical Union, Washington, 137-148, 1989.

Duchkov, A. D. and Sokolova, L. S.: Investigation of temperature changes at the Earth's surface via borehole geothermometry, in: Problems of climatic recontruction and enviroment of the Holocene and Pleistocene in Siberia (in Russian), 1, 151-157, Nauk, Novosibirsk, Russia, 1998.

Eston, S. M., Hamza, V. M., Becker, E. A., and Furumoto, S.: Geothermal research in exploration of hydrocarbons in the Paraná basin (in Portuguese), Internal Report, No. 18106, Instituto de Pesquisas Tecnológicas, São Paulo, Brazil, 1982.

Golovanova, I. V., Harris, R. N., Selezniova, G. V. and Stulc, P.: Evidence of climate warming in the southern Urals region derived from borehole temperatures and meteorological data, Global and Planetary Change, 29, 167-188, 2001.

Gomes, A. J. L.: Assessment of Geothermal Resources of the state of Rio de Janeiro (in Portuguese), Unpublished M.Sc. Thesis, National Observatory, Rio de Janeiro (Brazil). 138pp, 2003.

Gomes, A. J. L. and Hamza, V. M.: Geothermal gradients and heat flow in the state of Rio de Janeiro, Brazilian J. of Geophysics, 23, 4, 325-348, 2005.

Gosnold, W. D., Todhunter, P. E. and Schmidt, W.: The borehole temperature record of climate warming in the mid continent of North America, Global and Planetary Change, 15, 33-45, 1997.

Hamza, V. M.: Terrestrial heat flow in the alkaline intrusive complex of Poços de Caldas, Brazil. Tectonophysics, 83, 45-62, 1982.

Hamza, V. M.: A proposal for continuous recording of subsurface temperatures at the sites of Geomagnetic field Observatories. Rev. Geofísica, 48, 183-198, 1998.

Hamza, V. M.: Recent climate changes in the southern hemisphere: the geothermal evidence (In Portuguese), Proceedings 2nd Congress of the Brazilian Geophysical Society, Salvador (BA), 971-973, 1991.

Hamza, V. M. and Cavalcanti, A. S. B.: Thermal imprints of changes in vegetation cover and climate patterns in borehole temperature profiles in Brazil (Abstract), IAGA-IASPEI Assembly, Hanoi, Vietnam, Book of Abstracts, 413-414, 2001.

Hamza, V. M., Cerrone, B. N., Gomes, A. J. L., Cardoso, R. A.: A Geothermal Climate Change Observatory in the Southern Hemisphere (Abstract), Proceedings of XXIII General Assembly, IUGG, Sapporo, Japan, v. A, p197, 2003.

Hamza, V. M., Eston, S. M., Araujo, R. L. C., Vitorello, I., and 
Ussami, N.: Brazilian Geothermal Data Collection - Series-1, Publication IPT No. 1109, 1-316, 1978.

Hamza, V. M., Frangipani, A. and Becker, E. A.: Geothermal Maps of Brazil (In Portuguese) Internal Report No. 25305, Instituto de Pesquisas Tecnologicas, São Paulo, Brazil, 1987.

Hamza, V. M. and Muñoz, M.: Heat flow map of South America, Geothermics, 25(6), 599-646, 1996.

Hamza, V. M., Ribeiro, F. B., and Becker, E. A.: Recent Climatic Changes in the Southern Hemisphere. XX General Assembly, IUGG, Vienna (Austria), 1991.

Hamza, V. M., Silva Dias, F. J. S., Gomes, A. J. L., and Terceros, Z. G. D.: Numerical and functional representations of regional heat flow in South América. Physics of the Earth and Planetary Interiors, 152, 223-256, 2005.

Harris, R. N. and Chapman, D. S.: Mid-Latitude (30-60 N) climatic warming inferred by combining borehole temperatures with surface air temperatures, Geophys. Res. Lett., 28, 747-750, 2001.

Huang, S., Pollack, H. N. Wang, J., and Cermak, V.; Ground surface temperature histories inverted from subsurface temperatures of two boreholes located in Panxi, SW China. Journal of Southeast Asian Earth Sciences, 12, 113-120, 1995.

Huang, S., Pollack, H. N., and Shen, P. Y.: Temperature trends over the past five centuries reconstructed from borehole temperatures, Nature, 403, 756-758, 2000.

Jones, W. Q. W., Tyson, P. D., and Cooper, G. P. R.: Modeling climate change in South Africa from perturbed borehole temperature profiles, Quaternary International, 57/58, 185-192, 1999.

Lachenbruch, A. H., Claudouhos, T. T., and Saltus, R. W.: Permafrost temperature and the changing climate, Proc. Fifth International Conference on Permafrost, Trondheim, Norway, 1-9, 1988.

Lachenbruch, A. H., Sass, J. H., and Marshall, B. V.: Changing Climate: Geothermal Evidence from Permafrost in the Alaskan Artic, Science, 234, 689-696, 1986.

Lachenbruch, A. H., Sass, J. H., Marshall, B. V., and Moses, T. H. Jr.: Permafrost, heat flow and geothermal regime at Prudhoe Bay, Alaska, J. Geophys. Res., 87, 9301-9316, 1982.

Lewis, T. and Wang, K.: Geothermal evidence for deforestation induced warming: Implications for the climatic impact of land development, Geophys. Res. Lett., 25(4), 535-538, 1998.

Majorowicz, J. A. and Safanda, J.: Composite surface temperature history from simultaneous inversion of borehole temperatures in western Canadian plains, Global Planetary Change, 29, 231-239, 2001.

Pollack, H. N. and Huang, S.: Climate reconstruction from subsurface temperatures, Ann. Rev. Earth. Planet. Sci., 28, 339-365, 2000.

Pollack, H. N. and Smerdon, J. E.: Borehole climate reconstructions: spatial structure and hemispheric averages, J. Geophys. Res., 109, D11106, doi:10.1029/2003JD004, 2004.

Pollack, H. N., Huang, S., and Smerdon, J. E.: Five centuries of climate change in Australia: The view from underground, J. Quat. Sci., 21(7), 701-706, 2006

Press, W. H., Flannery, B. P., Teukolsky, S. A., and Vetterling, W. T.: Numerical Recipes: The Art of Scientific Computing. Cambridge University Press, Cambridge (U.S.A.), pp 818, 1986.

Rajver, D., Safanda, J. and Shen, P. Y.: The climate record inverted from borehole temperatures in Slovenia, Tectonophysics, 291, 263-276, 1998.
Ribeiro, F.: Study of the problem of determination of equilibrium temperatures in boreholes (in Portuguese), Unpublished Ph.D. Thesis, University of São Paulo, São Paulo, Brazil, 187pp, 1988.

Ribeiro, F.: Reconstruction of the climate change from geothermal profiles: Advances in Theory (in Portuguese), Proceedings 2nd Congress of the Brazilian Geophysical Society, Salvador (BA), 959-964, 1991.

Rimi, A.: Evidence of recent warming in the north of Morocco from disturbed geothermal gradients, Geodinamica Acta 1, 1927, 2000 .

Roy, S., Harris, R. N., Rao, R. U. M., and Chapman, D. S.: Climate change in India inferred from geothermal observations, J. Geophys. Res., 107(B7), 1-16, 2002.

Safanda, J. and Rajver, D.: Signature of last ice age in the present subsurface temperatures in the Czech Republic and Slovenia, Global and Planetary Change, 29, 241-257, 2001.

Santos, J.: Heat flow density measurements in the northern parts of the Paraná basin (in Portuguese), Unpublished M.Sc. Thesis, University of São Paulo, São Paulo, Brazil, 124pp, 1986.

Santos, J., Hamza, V. M., and Shen, P. Y.: A method for measurement of terrestrial heat flow density in water wells, Brazilian J. Geophysics, 4, 45-53, 1986.

Shen, P. Y. and Beck, A. E.: Least square inversion of borehole temperature measurement in functional space, J. Geophys. Res., 96, 199650-19 979, 1991.

Shen, P. Y. and Beck, A. E.: Palaeoclimate and heat flow density inferred from temperature data in the Superior Province of the Canadian Shield, Global and Planetary Change, 98, 143-165, 1992.

Shen, P. Y. Wang, K., Beltrami, H., and Mareschal, J.-C.: A comparative study of inverse methods for estimating climatic history from borehole temperature data, Palaeogeography, Palaeoclimatology, Palaeoecology, 98, 113-127, 1992.

Shen, P. Y., Pollack, H. N., and Huang, S.: Inference of ground surface temperature history from borehole temperature data: a comparison of two inverse methods, Global and Planetary Change, 14, 49-57, 1996.

Souza, J. R. S., Araújo, R. L. C., and Makino, M.: Transient variations in shallow thermal profiles associated with microclimatic changes in the Amazon (in Portuguese), Proceedings 2nd Congress of the Brazilian Geophysical Society, Salvador (BA), 965-970, 1991.

Stulc, P., Golovanova, I. V., and Selezniova, G. V.: Climate change record in the Earth - Example of borehole data analysis in the Urals region, Russia, Phys. Chem. Earth, 23, 1109-1114, 1998.

Taniguchi, M., Williamson, D. R., and Peck, A. J.: Disturbances of temperature-depth profiles due to surface climate change and subsurface water flow: 2. An effect of step increase in surface temperature caused by forest clearing in southwestern Australia, Water Resour. Res., 35, 1519-1529, 1999a.

Taniguchi, M., Williamson, D. R., and Peck, A. J.: Estimations of surface temperature and subsurface heat flux following forest removal in the south-west of Western Australia, Hydrological Processes, 12, 2205-2216, 1999b.

Tarantola, A. and Valette, B.: Inverse problems = quest for information, J. Geophys., 50, 159-170, 1982.

Torok, S. and Nicholls, N.: An historical temperature record for Australia, Aust. Met. Mag., 45, 251-260, 1996.

Tyson, P. D., Mason, S. J., Jones, M. Q., and Cooper, G. R.: Global 
warming and geothermal profiles: the surface rock-temperature response in South Africa, Geophys. Res. Lett., 25, 2711-2713, 1998.

Vasseur, G., Bernard, Ph., van de Mentebrouch, J., Kast, Y., and Jolivet, J.: Holocene palaeotemperatures deduced from geothermal measurements, Paleogeography, Paleoclimatology, Palaeontology, 43, 237-259, 1983.
Vitorello, I.: Heat flow and radiogenic heat production in Brazil, with implications for thermal evolution of continents. Ph. D. dissertation, Univ. of Michigan, Ann Arbor, U.S.A., 1978.

Vitorello, I., Hamza, V. M., Pollack, H. N., and Araújo, R. L. C.: Geothermal Investigations in Brazil, Rev. Bras. Geof., 8(2), 7189, 1978 